\title{
An Augmented Reality-Based Framework for Assisting Individuals with Autism and Cognitive Disorders
}

\author{
Vladimir Geroimenko, Samir El-Seoud, and Osama Halabi
}

\begin{abstract}
People with autism require systematic assistance while dealing with the surrounding environment and its objects. The project aim is to develop a framework that could be of substantial help to people with autism and cognitive disorders. The framework is based on common mobile devices and freely available Augmented Reality (AR) applications. The Augmented Reality used in our approach is marker-based AR that employs a camera and a visual marker to trigger and present media content on the mobile device's screen. The developed framework allows parents and teachers to easily create educational augmented environments for children with autism and cognitive disorders by populating a real-world space with visual markers of favorite cartoonish helpers that can evoke helpful AR content and embed it in the real-world environment. The paper analyzes and discusses the use of the proposed framework from conceptual and technological points of view.
\end{abstract}

Index Terms-Autism and cognitive disorders, educational augmented environments, new learning models and applications.

\section{INTRODUCTION}

People with autism spectrum disorder require systematic assistance while dealing with the surrounding environment, its objects and particular boundaries.

Many studies have explored the utilization of technology as assistive therapeutic tools for autism, namely computer technology [1], robotics systems [2], and Virtual Reality [3]. In recent years, Augmented Reality (AR) technology is being used successfully in the gaming industry [4], medicine [5], art [6], assistive technology [7], [8], education [9], [10] and other areas.

A systematic review of the literature on advantages and challenges associated with Augmented Reality for education identified an increase in the number of AR studies during the last four years and has revealed that the most reported advantage of Augmented Reality is that it promotes enhanced learning achievement [11]. In particular, Augmented Reality technology allows promising results to be achieved in non-traditional learning environments specially constructed for people with autism and cognitive disabilities. See, for example, [12]-[14] as well as the latest publications in this area, such as [15]-[17].

Manuscript received January 11, 2018; revised June 28, 2018

V. Geroimenko and S. El-Seoud are with the Faculty of Informatics and Computer Science, the British University in Egypt, Sherouk City, Cairo, Egypt (e-mail: vladimir.geroimenko@bue.edu.eg, samir.elseoud@bue.edu.eg).

O. Halabi is with the Computer Science and Engineering Department, College of Engineering, Qatar University, Doha, Qatar (e-mail: ohalabi@qu.edu.qa).
The principal aim of this project is to develop a general framework that could be of substantial help to people with autism and cognitive disorders. The framework is based on the use of common mobile devices (such as smartphones or tablet computers) and freely available Augmented Reality applications (such as Layar, Aurasma or others). The Augmented Reality used in our approach is marker-based AR that employs a camera and a visual marker to trigger and present media content (3D animation, video, audio, image, text or their multimedia combination) on the mobile device's screen as if the content is embedded in the real-world environment. For the description and analysis of different types of Augmented Reality, see [18]. Basically, there are the following two types of Augmented Reality: marker-based and location-based [19]. We have chosen the marker-based AR, because in this phase of the project, our research objectives are limited to cognitive environments within a building. If, in the future, we decide to explore larger scale environments (such as a park or a city), then location-based AR will be the technology of choice. In this case, the images of a virtual helper should probably be presented on big AR billboards placed in a variety of locations across the larger environment.

\section{A GENERAL AR FrAMEWORK FOR ASSISTING Cognitively Challenged PeRsons}

\section{A. The Selection of the Approach and Its Components}

The search for the most appropriate and effective types of visual AR markers comprised the initial and highly critical part of the project. It resulted in the following findings.

Firstly, to get the visual appearance of the assistant, the disabled persons should choose a favorite character by themselves; it can be one from a cartoon film, comic book or computer game.

In the prototype, shown and discussed in this paper, the chosen favorite character is Mario - a short and pudgy Italian plumber that has appeared as a fictional character in the Super Mario platform game series (in over 200 video games since his creation), owned by Nintendo [20].

Mario is just an example character used in our prototype. The number of cartoon heroes is huge (see, for instance, various top 25, top 50 and top 100 lists of most popular cartoon characters at [21]-[23]). This quantity and variety can be considered as one of the merits of the proposed framework, because it allows any disabled person not only to choose an assistant, but also to make available hundreds of the character's postures, which can serve as attractive AR markers.

This kind of AR markers has several other advantages, 
which are relevant to their use for individuals with autism and cognitive disorders: the beloved character is being perceived by the cognitively challenged individual in a positive way as a genuine assistant that is ready to help with advice in a difficult situation; the stickers/markers placed on real-world objects are most recognizable and identifiable by the disabled person; a large variety of the character's body postures (available as animation frames - see, for example, Fig. 1) facilitates the production of any required number of unique $\mathrm{AR}$ markers and therefore to cover/trigger any amount of AR multimedia content.
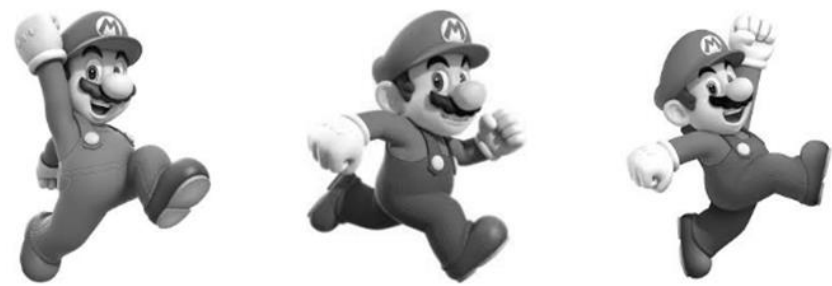

Fig. 1. A sample choice of character postures that can be used as a friendly assistant for visual AR markers (Mario from Nintendo's game series [24]).

After the successful selection, the chosen character is to be printed on sticky labels that can then be attached to any object in the surrounding real-world environment in order to serve as visual markers, as shown in Fig. 2.

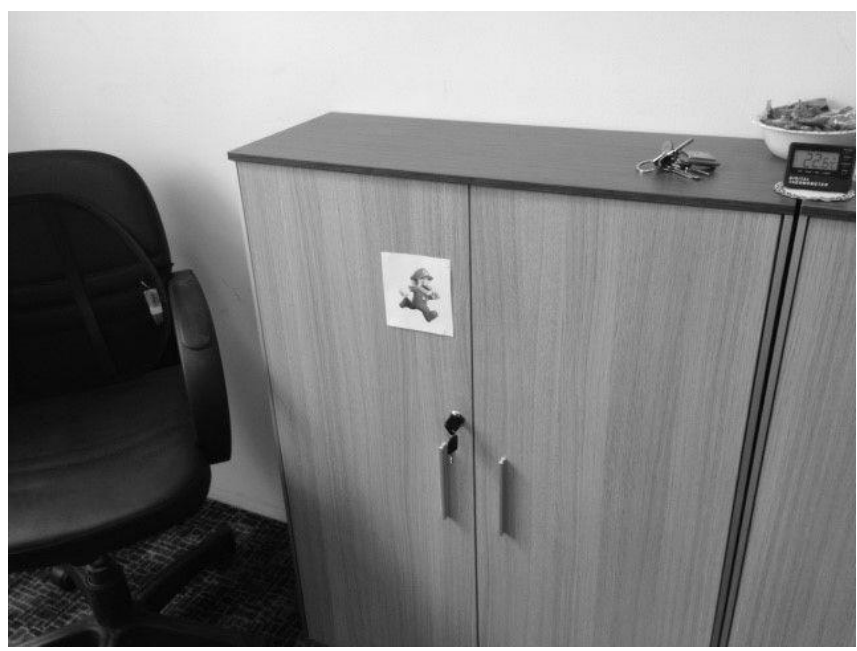

Fig. 2. A visual AR marker/sticker with an image of Mario computer game character attached to a real-world object.

The choice of an effective type of AR multimedia content was another challenging task of the research. It was found that the use of particular media types (video, audio, image or text) in general depends on specific tasks, situations, and the problems to be solved. However, from the use of Augmented Reality as a cognitive tool, the most powerful effects seem to be produced by videos, 'embedded' in the real world. The idea of using video is well supported by some previous research publications. See, for example: [25]-[28].

This type of 'talking head' videos with a transparent background can be produced relatively easily. Their advantage lies in the illusion that they exist in the surrounding real world, rather than on the screen of the mobile device. See Fig. 3.

Another effective media type could be provided by audio augmentation of the real-world objects and environments by 'attaching' sound-only files to the markers/objects.

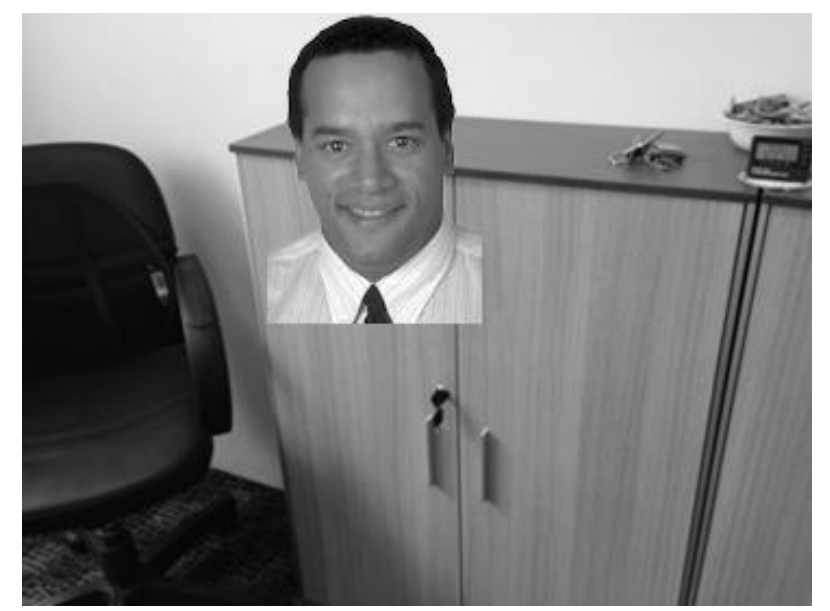

Fig. 3. An AR video object triggered by the marker and embedded in the real-world environment (as displayed in the AR viewer on the iPad screen).

\section{B. Working Prototype and Implementation of the Framework}

In the current first phase of the project, the problem was thoroughly analyzed and possible solutions and requirements were proposed. This has led to the production of a working prototype of the anticipated framework and its testing it 'in vitro' for its technical and some special experimental functionalities.

The prototype used the Mario game character as an assistant presented in the form of printed AR markers on a variety of real-world objects within a particular learning environment. See Fig. 1, 2 and 3 for more details.

Our research on the market of freely available and easy to use AR software platforms and tools concluded that at the moment the best one is the Aurasma platform by Hewlett-Packard Development Company [29]. It is available as a free app for iOS- and Android-based mobile devices. Also, it includes the Aurasma Studio that is easy to use and that can successfully be handled by teachers with any level of computer skills. Technologically, the Aurasma Studio also allows us to implement all the AR-related features of the proposed framework. However, we keep searching the AR software market for new arrivals with novel approaches and functionalities.

As expected, the prototype has shown good and stable technical characteristics conforming to the main working hypothesis of the project. It can be populated with any other assistant/marker characters and can be used within any small-scale environments. These are relevant technical results for the general AR framework researched and proposed in the project.

\section{CONCLUSIONS AND FUTURE WORK}

Our working hypothesis is that the developed framework allows parents and teachers to easily create educational augmented environments for children with autism and cognitive disorders by populating a real-world space with visual markers of favorite cartoonish helpers that are able to evoke assisting AR content embedded in the real-world environment. 
The next phase of the project will include a short field test of the prototype in order to enable its fine-turning and debugging on several AR platforms and applications. After this, the final phase of full-scale implementation of the proposed general AR framework is planned. It will involve a group of individuals with autism and/or other cognitive disorders. The results of the experimental study of the framework will be carefully analyzed and published.

\section{REFERENCES}

[1] R. W. Picard, "Future affective technology for autism and emotion communication," Philos. Trans. R. Soc. Lond. B. Biol. Sci., vol. 364 no. 1535,2009 , pp. $3575-3584$.

[2] G. Pioggia, M. L. Sica, M. Ferro, R. Igliozzi, F. Muratori, A. Ahluwalia, and D. Rossi, "Human-robot interaction in autism: FACE, an android-based social therapy," in Proc. IEEE International Workshop on Robot and Human Interactive Communication, 2007, pp. 605-612.

[3] O. Halabi, S. Elseoud, and V. Geroimenko, "Teaching design project in introductory engineering course using 3D modelling and immersive virtual reality," presented at 20th International Conference on Interactive Collaborative Learning (ICL2017), 2017, Budapest, Hungary.

[4] K. Lombardi, A. Pourmand, E. Kuhl, and F. O'Connell, "Videogame-related illness and injury: A review of the literature and predictions for Pokemon GO!' George Washington University, School of Medicine and Health Sciences, 2017.

[5] H. Ha and J. Hong, "Augmented reality in medicine," Hanyang Medical Reviews, 2016, vol. 36, no. 4, pp. 242-247.

[6] V. Geroimenko, "Augmented reality technology and art: The analysis and visualization of evolving conceptual models," in Proc. the 16th International IEEE Conference on Information Visualisation (IV2012), IEEE Computer Society: Los Alamitos, CA, USA, 2012, pp. 445-453.

[7] O. Halabi, S. Elseoud, J. M. Alja'am, H. Alpona, M. Al-Hemadi, and D. Al-Hassan, "Immersive virtual reality in improving communication skills in children with autism," International Journal of Interactive Mobile Technologies (iJIM), 2017, vol. 11, no. 2, pp. 146-158.

[8] O. Halabi, S. El-Seoud, J., Alja'am, H. Alpona, M. Al-Hemadi, D. Al-Hassan, "Design of immersive virtual reality system to improve communication skills in individuals with autism," International Journal of Emerging Technologies in Learning (iJET), vol. 12, no. 5, pp. 50-64, 2017.

[9] M. Akçayıra and G. Akçayırb, "Advantages and challenges associated with augmented reality for education: A systematic review of the literature," Educational Research Review, Elsevier, vol. 20, pp. 1-11, June 2017.

[10] O. Halabi, M. Al-Ansari, F. Al-Mesaifri, R. Al-Shaabi, Y. Halwani, A. Fatma, R. Al-Shaabi, and F. Al-Mesaifri, "Navigation aid for blind people using depth information and augmented reality technology," in Proc. NICOGRAPH International, 2012, pp. 120-125.

[11] M. Akçayıra and G. Akçayırb, "Advantages and challenges associated with augmented reality for education: A systematic review of the literature," Educational Research Review, Elsevier, vol. 20, pp. 1-11, June 2017.

[12] C. Chung and C. Chen, "Augmented reality based social stories training system for promoting the social skills of children with autism,' Advances in Ergonomics Modeling, Usability \& Special Populations. Advances in Intelligent Systems and Computing, Springer, 2017, vol. 486, pp. 495-505.

[13] P. Cunha, J. Brandão, J. Vasconcelos, F. Soares, and V. Carvalho, "Augmented reality for cognitive and social skills improvement in children with ASD," in Proc. 13th International Conference on Remote Engineering and Virtual Instrumentation (REV), February 2016, UNED, Madrid, Spain, pp. 215-223.

[14] E. Hosseini and F. Foutohi-Ghazvini, "Play therapy in augmented reality children with autism," Journal of Modern Rehabilitation, 2016, vol. 10, no. 3, 2017. pp. 110-115.

[15] G. Herrera, L. Vera, J. Sevilla, C. Portalés, S. Casas, "On the development of VR and AR learning contents for children on the autism spectrum: From real requirements to virtual scenarios," Augmented Reality for Enhanced Learning Environments, 2018, pp. 106-141.

[16] N. T. Sahin, R. Abdus-Sabur, N. U. Keshav, R. Liu, J. P. Salisbury, and A. Vahabzadeh, Augmented Reality Intervention for Social
Communication in Autism in a School Classroom: Rated by Teachers and Parents as Effective and Usable in a Controlled, Longitudinal Pilot Study, 2018.

[17] M. Lumbreras, M. Lourdes, and S. Ariel, "Aura: Augmented reality in mobile devices for the learning of children with ASD - Augmented reality in the learning of children with autism," Augmented Reality for Enhanced Learning Environments, 2018, pp. 142-169.

[18] V. Geroimenko, Augmented Reality Art: From an Emerging Technology to a Novel Creative Medium, $2^{\text {nd }}$ Edition, Springer-Verlag, 2018, p. 384.

[19] V. Geroimenko, "Augmented reality technology and art: The analysis and visualization of evolving conceptual models," in Proc. the 16th International IEEE Conference on Information Visualisation (IV2012), IEEE Computer Society: Los Alamitos, CA, USA, 2012, pp. 445-453.

[20] Mario Games - Nintendo's Official Home for Super Mario. [Online]. Available: http://mario.nintendo.com

[21] The 100 Greatest Cartoon Characters of all Time. [Online]. Available: http://www.listal.com/list/100-greatest-cartoon-characters-all

[22] Top 25 most popular cartoon characters. [Online]. Available: http://topstuffz.blogspot.com.eg/2011/11/top-25-most-popular-cartoo n-characters.html

[23] Top 50 Cartoon Characters of All Time. [Online]. Available: https://www.thoughtco.com/top-cartoon-characters-of-all-time-13760 6

[24] Mario Games - Nintendo's Official Home for Super Mario. [Online] Available: http://mario.nintendo.com

[25] K. M. Ayres and J. Langone, "Intervention and instruction with video for students with autism: A review of the literature," Education and Training in Developmental Disabilities, 2005, vol. 40, no. 2, pp. 183-196.

[26] Z. Bai, A. F. Blackwell, and G. Coulouris, "Using augmented reality to elicit pretend play for children with autism," IEEE Transactions on Visualization and Computer Graphics, 2015, vol. 21, no. 5, pp. $598-610$.

[27] M. H. Charlop-Christy, L. Le, and K. A. Freeman, "A comparison of video modeling with in vivo modeling for teaching children with autism," Journal of Autism and Developmental Disorders, 2000, vol. 30 , no. 6, pp. 537-552.

[28] R. Shipley-Benamou, J. R. Lutzker, and M. Taubman, "Teaching daily living skills to children with autism through instructional video modeling," Journal of Positive Behavior Interventions, 2002, vol. 4, no. 3, pp. 166-177.

[29] Aurasma. [Online]. Available: http://www.aurasma.com

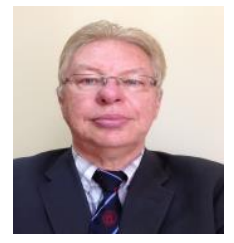

Vladimir Geroimenko received his M.Sc. degree in physics and mathematics from Vitebsk State University (1976), $\mathrm{PhD}$ degree in the methodology of science from Belarusian Academy of Sciences (1982) and a higher D.Sc. (doctor of science) degree in cognitive sciences from Belarusian State University (1990).

From 1982 to 1998 , he worked at the Belarusian Academy of Sciences. From 1991 to 1993, he was Research Fellow of the Alexander von Humboldt Foundation at the Ruhr-University Bochum in Germany, and from 1995 to 1998 - Visiting Professor at SSKKII Centre for Cognitive Science, Göteborg University, Sweden. In 1998, he joined the University of Plymouth in the UK as Reader in Multimedia and Web Technology. In September 2016, he joined the British University in Egypt, Cairo.

Prof. Geroimenko has published 160 scientific works, including 15 books and 39 book chapters. He was the principal editor of research monographs "Visualizing the Semantic Web: XML-based Internet and Information Visualization", $2^{\text {nd }}$ ed., Springer, 2006 and "Augmented Reality Art: From an Emerging Technology to a Novel Creative Medium", 2nd ed., Springer, 2018.

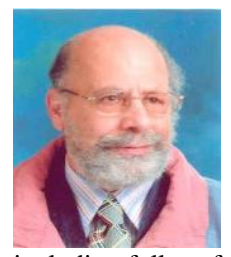

Samir El-Seoud received his B.Sc. degree in physics, electronics and mathematics from Cairo University in 1967, his higher diplom in computing from Technical University of Darmstadt (TUD) /Germany in 1975 and his doctor of science from the same University (TUD) in 1979 .

He held different academic positions at TUD, including full-professor in 1987. He spent different years as a full-professor of computer science at SQU - Oman, Qatar University, and PSUT-Jordan and acted as a head of computer science for many years. He worked as scientific advisor and consultant for the GTZ in Germany and was 
responsible for establishing a postgraduate program leading to M.Sc. degree in Computations at Colombo University / Sri-Lanka (2001 - 2003).

Prof. El-Seoud joined The British University in Egypt (BUE) in 2012 Currently, he is Basic Science Coordinator at the Faculty of Informatics and Computer Science (ICS) at BUE. Professor El-Seoud has more than 130 publications in international proceedings and international reputable journals.

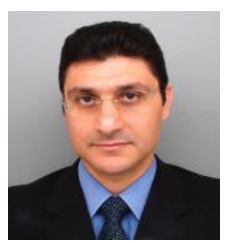

Osama Halabi received M.Sc. degree in computer science from Shanghai University, and Ph.D. degree in information science from Japan Advanced Institute of Science and Technology (JAIST) in 1998, and 2001, respectively.

He was a Fujitsu endowed chair (Fujitsu Co.,) at Japan Advanced Institute of Science and Technology from 2001 to 2003, a researcher in Virtual Systems Laboratory at Gifu University from 2003 to 2006, an assistant professor at Iwate University, Japan, from 2006 to 2010 . He is currently an assistant professor at Qatar University, Qatar. He is the author of more than 50 refereed technical papers in international conferences and journals, 35 short conference articles and technical reports, two books, and one patent.

Dr. Halabi was a recipient of the IEEE Information and Communication Systems Best Conference Paper Award in 2017, and many awards in prestigious technology completions. His research interests include virtual reality, haptic interface, human-computer interaction, game development, and computer graphics. He is a member of IEEE, ACM, Virtual Reality Society of Japan (VRSJ), and The Society for Art and Science in Japan. 